\title{
Experimental Reinforcement Agent for Damaged Walls of Payathonzu Temple Murals in Bagan, Myanmar
}

\author{
$\mathrm{Na}$ Ra Lee, Hwa Soo Lee, Kyeong Soon Han ${ }^{*}$ \\ Institute of Conservation of Paintings, Konkuk University, Chungju 27278, Korea
}

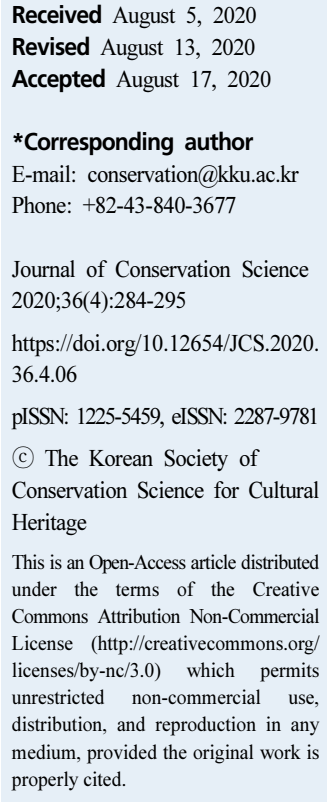

\begin{abstract}
This study focuses on reinforcement agents for wall damage, such as cracks, breakage, or delamination, for mural paintings from the Payathonzu temple. Experiments were conducted with filling and grouting agents based on the reinforcing method. In the filling reinforcement experiment, different mixing ratios of lime to sand, and additives (jaggery, seaweed glue, and Primal SF-016) were used. In the grouting reinforcement experiment, the mixing ratio of lime and pozzolan was the same, and the additive types were identical to the filling reinforcement experiment. The filling reinforcement experiment showed that there were fewer physical changes such as contraction, with a greater mixing ratio of lime to sand, however, the compressive strength decreased as the mixing ratio increased. With additives, the change in volume of agent decreased and the compressive strength increased, which was especially prominent for jaggery and Primal SF-016. The grouting reinforcement experiment showed that there was a remarkable contraction with an increased amount of moisture that originates from the characteristic of grouting agents that requires flowability. With additives, the water content of the agent decreased, whereas the compressive strength and adhesion increased. Among the additives, Primal SF-016 exhibited the highest compressive strength, and seaweed glue exhibited the most considerable viscosity and adhesion. The study results showed that the characteristics of reinforcement agents vary according to the mixing ratio and additives of the filling and grouting agents. Therefore, it is necessary to selectively apply the mixing ratio and additives for different reinforcement agents considering the wall damage for conservation treatments.
\end{abstract}

Key Words Payathonzu temple, Mural paintings, Reinforcement, Filling, Grouting, Conservation

\section{INTRODUCTION}

The ancient city of Bagan in Myanmar is one of the top three Buddhist sites in the world with remains such as temples, pagodas, and monasteries from the $11^{\text {th }}$ and $13^{\text {th }}$ centuries. Among these remains, the Payathonzu temple $\left(13^{\text {th }}\right.$ century) is the only temple in Bagan consisting of three temples in a row. The murals inside the temple made of piled bricks as the support layer, lime plasters, and the painting layer was executed by the Secco technique (Korea Culture Heritage Foundation et al., 2019). According to the 2018 evaluation results of the conservation state of the murals in Payathonzu temple, the physical properties of the walls were significantly degraded due to damages such as cracks, breakage, and separation between layers. In particular, the upper part of the walls or the corridor ceilings were severely damaged due to cracks, flaking, and delamination of the walls. Repairs conducted in the past were also damaged, cracked, or separated from the wall due to differences in physical properties between the repair materials and the original wall (Korea Culture Heritage Foundation et al., 2018).

Regarding the conservation treatment of mural paintings, reinforcement works should not be performed by a single method, and different materials and techniques should be applied depending on the materials used for each mural and their related damage. Filling agents should be applied if the stability of the mural surface is reduced due to cracks and other damage, and grouting agents should be used to maintain the stability of the areas at risk of exfoliation or collapse due 
to separation between layers.

Research on wall reinforcement began in the early 1980s with a study on grout (The International Centre for the Study of the Preservation and Restoration of Cultural Property, 1982) which is injected to preserve the surface of structures such as murals and mosaics, followed by studies employing various materials such as hydraulic lime, pozzolan, and carbonate ester materials (Isobel, 2004; Piero et al., 1997). A study on grout characteristics (Francesca et al., 2005) was also conducted based on the mixing ratio of materials and developed grout technologies applicable to murals. Grouts were used to preserve murals in the tomb of Queen Nefertari in Egypt and the Cave 85 at Mogao Grottoes in Dunhuang (Miguel and Mahasti, 1993; Stephen et al., 2010), but difficulties in comparing or selecting grout properties were experienced due to the lack of quantitative evaluation methods. Therefore, continuous research is conducted by the Getty Conservation Institute to systematically evaluate and compare grouts, although with limited use in the application of conservation treatment (Beril and Leslie, 2013; 2014).

Wall reinforcement studies conducted in Korea include studies on the physical properties according to the type of reinforcing medium mixed with the mixing ratio of the finishing layer or reinforcement agent for earthen murals (Kim and Jeong, 2008; Lee et al., 2013b; Moon, 2018). Recent studies include an experimental study examining the cause of damage according to the material properties of the finishing layer of ancient tomb murals (Cho et al., 2017), and a study on reinforcements using natural hydraulic lime taking into consideration the humid environmental conditions ( $\mathrm{Yu}$ and Lee, 2019).

Filling and grouting works for conservation were performed on many temple murals in Bagan, Myanmar from the 1970s to the present day. However, systematic studies on how to reinforce walls according to the damage of the murals were still insufficient. To reinforce the degraded walls, firstly, a thorough examination should be performed on the reinforcement technologies and materials that will be required according to the observed damage. In the case of the Payathonzu temple murals, reinforcement works were conducted several times in the past. The properties of the walls and types of damage were not tested and validated. Therefore, this study conducted physical property tests and evaluations on filling and grouting reinforcement agents that can be effec- tively applied to major damage to walls, such as cracks, fractures, and separation between layers for the stable conservation treatment of the murals in Payathonzu temple.

\section{MATERIALS AND METHOD}

\subsection{Materials for experiments}

The middle layers of the murals in the Payathonzu temple are decorated with approximately $5 \sim 7 \mathrm{~mm}$ lime plasters, with a support layer composed of piled bricks. The finishing layer on top of the middle layer consists of approximately 3 5 mm thick lime plasters (Lee et al., 2019).

This study selected lime, sand, and pozzolan as the reinforcement mortar materials after considering the lime plaster material properties of the Payathonzu temple murals and the materials recently used to reinforce the walls in other temples in Bagan, Myanmar (Figure 1). Lime was used in different ways according to the experiments conducted in this study. In the filling reinforcement experiment, lime (Calcium oxide, Baekkwang Mineral Products Co., Ltd., KOR) was used in the form of slaked lime, produced by a greater than six months wet-slaking process, after referring to a method of processing lime in Bagan (Ahn et al., 2018; Korea Culture Heritage Foundation et al., 2019). The lime for the grouting reinforcement experiment was injection lime (Injection Mortar PLM-A, Kremer Pigmente GmbH\&Co.KG, DEU), which is used for mural conservation abroad. ISO standardized sand (EN 196-1, SNL, FRA) was used to produce specimens to test the compressive and flexural strengths of the cement mortar in compliance with KSL ISO 679. Pozzolan (Micronizzata Roman Gray Pozzolana, CTS, ITA) is used for mural conservation abroad and was specifically used in this experiment as an admixture. The additives mixed to make the reinforcement agent samples were jaggery of Myanmmar (found to be mixed to make Payathonzu temple murals), seaweed glue of Korea (traditionally used on Buddhist murals in Korea as a conservation treatment), and Primal SF-016 (Primal $^{\mathrm{TM}}$ SF-016 ER Acrylic Emulsion, Rohm and Haas Chemical Industrial Co., Ltd., TWN) (hereinafter referred to as "primal") instead of Primal AC-33, whose production was suspended and was among the acrylic emulsions recorded as an additive for the Bagan temple murals (Figure 2). The concentration of the additives was jaggery $10 \%$, seaweed glue 


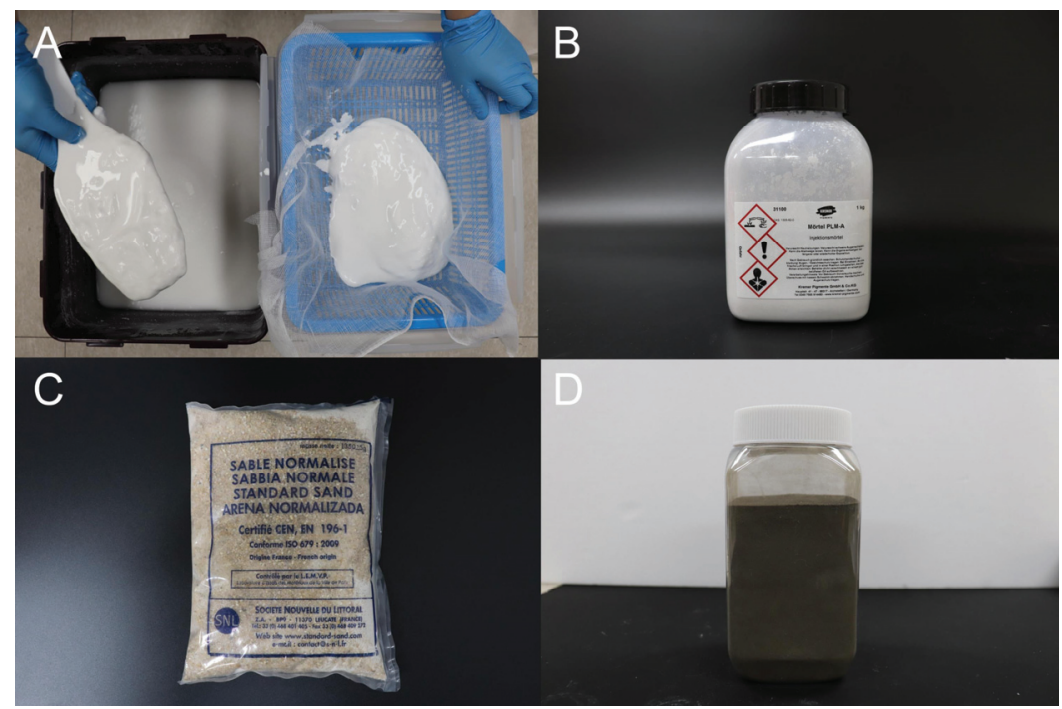

Figure 1. Mortar materials. (A) slaked lime, (B) injection lime, (C) standard sand, (D) pozzolan.

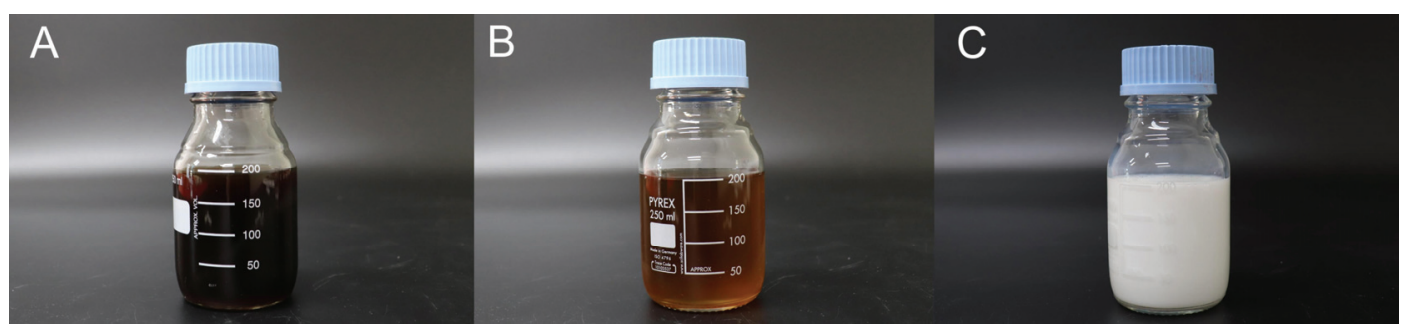

Figure 2. Additives. (A) jaggery $10 \%$, (B) seaweed glue 3\%, (C) primal $5 \%$.

Table 1. Viscosity and $\mathrm{pH}$ of additives

\begin{tabular}{ccc}
\hline & Viscosity $(\mathrm{cP})$ & Acidity $(\mathrm{pH})$ \\
\hline Jaggery $10 \%$ & 6.12 & 6.47 \\
Seaweed glue $3 \%$ & 12.57 & 6.72 \\
\hline Primal $5 \%$ & 5.51 & 7.56 \\
\hline
\end{tabular}

$3 \%$, and primal $5 \%$ after consideration of the properties and the concentrations of the additives applied at the wall painting conservation treatment site (Baekje Cultural Properties Research Institute, 2010; Rodolfo, 2018; The International Centre for the Study of the Preservation and Restoration of Cultural Property, 1993). Table 1 lists the viscosity and acidity of the additives.

\subsection{Sample production}

Samples were divided into two depending on the wall reinforcement method, namely filling agents, to fill fractures or missing parts and grouting agents, to fill cracks and delaminated sections. A total of 12 filling agent samples were prepared by mixing lime and sand, no larger than very coarse sand (under $1.00 \mathrm{~mm}$ ), with additives according to different mixing ratios $(1: 1,1: 2,1: 3)$ based on weight. A total of four grouting agent samples were prepared by mixing lime and pozzolan, at a 1:1 ratio based on weight, with the additives. Distilled water was used instead of additives as the control group to evaluate each condition, and Table 2 lists the primary materials, mixing ratios, and additives used to prepare each sample. The content of the additives was selected within a specific range based on results from mortar workability pre-tests. 
Table 2. List of the reinforcement agent samples

\begin{tabular}{|c|c|c|c|c|c|c|}
\hline \multirow{2}{*}{\multicolumn{2}{|c|}{ Classification }} & \multirow{2}{*}{ Sample name } & \multicolumn{2}{|l|}{ Mortar } & \multicolumn{2}{|c|}{ Additive } \\
\hline & & & Material & Ratio & Material & Content (wt $\%$ ) \\
\hline \multirow{12}{*}{$\begin{array}{l}\text { Filling } \\
\text { agent } \\
\text { samples }\end{array}$} & \multirow{4}{*}{$\mathrm{F} 1$} & F1-J & \multirow{4}{*}{ Lime : Sand } & \multirow{4}{*}{$1: 1$} & Jaggery & 0.02 \\
\hline & & F1-S & & & Seaweed glue & 0.04 \\
\hline & & F1-P & & & Primal & 0.02 \\
\hline & & F1-W & & & Water & 0.02 \\
\hline & \multirow{4}{*}{$\mathrm{F} 2$} & F2-J & \multirow{4}{*}{ Lime : Sand } & \multirow{4}{*}{$1: 2$} & Jaggery & 0.03 \\
\hline & & F2-S & & & Seaweed glue & 0.07 \\
\hline & & F2-P & & & Primal & 0.03 \\
\hline & & F2-W & & & Water & 0.04 \\
\hline & \multirow{4}{*}{ F3 } & F3-J & \multirow{4}{*}{ Lime : Sand } & \multirow{4}{*}{$1: 3$} & Jaggery & 0.06 \\
\hline & & F3-S & & & Seaweed glue & 0.11 \\
\hline & & F3-P & & & Primal & 0.05 \\
\hline & & F3-W & & & Water & 0.07 \\
\hline \multirow{4}{*}{$\begin{array}{l}\text { Grouting } \\
\text { agent } \\
\text { samples }\end{array}$} & \multirow{4}{*}{ G } & G-J & \multirow{4}{*}{ Lime : Pozzolan } & \multirow{4}{*}{$1: 1$} & Jaggery & 0.53 \\
\hline & & G-S & & & Seaweed glue & 0.53 \\
\hline & & G-P & & & Primal & 0.47 \\
\hline & & G-W & & & Water & 0.47 \\
\hline
\end{tabular}

\subsection{Evaluation methods}

Evaluation was performed by visual inspection, color measurement, and examining physical properties such as chromaticity, contraction, weight change and water content, compressive strength, viscosity, and adhesion. Table 3 lists the evaluation methods and the types of samples for each experiment, in which the mean was used by measuring the samples for each condition three times.

\subsubsection{Visual appearance}

A DSLR camera (EOS 800D, Canon, JPN) was used to examine physical changes such as changes in color, cracks, or contraction observed on the surface. Adobe Photoshop CC 2017 was used to calculate the crack area by obtaining the pixel ratio of the crack to the total area.

\subsubsection{Chromaticity}

Chromaticity was measured with a Chromameter (CR-400, Konica Minolta, JPN) to compare the color difference according to the mixing ratios and types of additives of reinforcement agent samples. Chromaticity values were based on the CIE LAB color space.

\subsubsection{Contraction}

Contraction was calculated to examine the shrinkage of the samples. In the filling reinforcement experiments, the lengths after preparing the samples and the lengths when change no longer occurred were measured with a digital Vernier caliper. In the grouting reinforcement experiments, 3D image data of the samples was acquired using a broadband scanner (Faro Focus S, FARO ${ }^{\circledR}, \mathrm{CAN}$ ) and a data alignment program (Faro SCENE, FARO ${ }^{\circledR}, \mathrm{CAN}$ ). The lengths of the $3 \mathrm{D}$ image data section were measured to calculate the difference from the authentic sample 3D image data without contraction. The authentic sample was made of gypsum. Deviation analysis was performed by a post-correction program (Polyworks, Innovmetric, CAN) and a deviation analysis program (Geomagic Control X, 3D Systems, USA) to visually compare the contraction deviation between the authentic sample and grouting agent samples. Deviation analysis was performed by overlapping the $3 \mathrm{D}$ image data of the samples; the size deviation was expressed in numerical values and color information. The closer the variation between the authentic sample and the grouting sample is to 0 , the greener it becomes. Lower variation positions display color values for blue, higher variation positions display red, 
Table 3. Classification of the evaluation methods

\begin{tabular}{|c|c|c|c|}
\hline Sample & & Methods & Sample type \\
\hline \multirow{6}{*}{$\begin{array}{l}\text { Filling } \\
\text { agent } \\
\text { samples }\end{array}$} & \multirow{2}{*}{$\begin{array}{l}\text { Visual } \\
\text { property }\end{array}$} & Visual appearance & \multirow{5}{*}{$\begin{array}{c}\text { Circle } \\
\varnothing 90 \times 15(\mathrm{~mm})\end{array}$} \\
\hline & & Chromaticity & \\
\hline & \multirow{4}{*}{$\begin{array}{l}\text { Physical } \\
\text { property }\end{array}$} & Weight change & \\
\hline & & Contraction & \\
\hline & & Water content & \\
\hline & & $\begin{array}{l}\text { Compressive strength } \\
\text { Curing period: } 7,28,56 \text { days }\end{array}$ & $\begin{array}{c}\text { Cube } \\
50 \times 50 \times 50(\mathrm{~mm})\end{array}$ \\
\hline \multirow{7}{*}{$\begin{array}{l}\text { Grouting } \\
\text { agent } \\
\text { samples }\end{array}$} & \multirow{2}{*}{$\begin{array}{l}\text { Visual } \\
\text { property }\end{array}$} & Visual appearance & \multirow{3}{*}{$\begin{array}{c}\text { Circle } \\
\varnothing 60 \times 15(\mathrm{~mm})\end{array}$} \\
\hline & & Chromaticity & \\
\hline & \multirow{5}{*}{$\begin{array}{l}\text { Physical } \\
\text { property }\end{array}$} & Water content & \\
\hline & & Weight change & \multirow{3}{*}{$\begin{array}{c}\text { Cylinder } \\
\varnothing 25 \times 25(\mathrm{~mm})\end{array}$} \\
\hline & & Contraction & \\
\hline & & $\begin{array}{l}\text { Compression strength } \\
\text { Curing period: } 7 \text { days }\end{array}$ & \\
\hline & & Viscosity \& Adhesion & Grout \\
\hline
\end{tabular}

and more significant deviations display darker color values.

\subsubsection{Weight change and Water content}

To compare the weight change caused by drying, weight change was calculated by measuring the weight of the samples after preparation and when weight change no longer occurred with an electronic balance (FX-300i, A\&D Company, Limited., JPN). To examine the maximum water content, the samples were air-dried and immersed in water for $24 \mathrm{~h}$. An electronic microbalance (High quality electronic balance, HANSUNG, KOR) was used to measure the weight of the samples after drying the surface.

\subsubsection{Compressive strength}

Compressive strength was measured using a universal testing machine (AGS-X, Dong-il SHIMADZU, KOR) at a $5 \mathrm{~mm} / \mathrm{min}$ loading speed. The curing periods were 1,4 , and 8 weeks for the filling agent samples and 4 weeks for the grouting agent samples.

\subsubsection{Viscosity and Adhesion}

In the grouting reinforcement experiments, a viscometer (DV2T, Brookfield, USA) and adhesion tester (PosiTest AT-A Automatic, DeFelsko Co., USA) were used to measure the viscosity and adhesive strength of the grouts according to the additives. The viscosity was measured five times for
$60 \mathrm{~s}$, under the conditions of a LV-4 Spindle, $30 \mathrm{rpm}$, and a reliability range of $10 \% \sim 100 \%$, to calculate the mean excluding the maximum and minimum values. In terms of the adhesion, the same weight of grouting agents was applied to the bottom of a $20 \mathrm{~mm}$ dolly then attached to the adherend. Bricks measuring $23 \times 11.4 \times 5 \mathrm{~cm}$ were used as the adherend. After a standoff and the surface of the adherend were positioned at right angles, the pressure of separating the dolly was measured 10 times to calculate the mean of the valid values.

\section{RESULTS AND DISCUSSION}

\subsection{Filling reinforcement agent experiment}

\subsubsection{Visual properties}

Surface observation of the filling agent samples showed differences according to the types of additives mixed with the mortar at the stipulated mixing ratios. Generally, cracks were not observed on the surface of the samples, but the lower the mixing ratio of sand to lime, the greater the change in volume was (Figure 3-5). Contraction occurs due to stress inside the sample as the moisture evaporates during the curing process. The control group and the seaweed glue and primal mixing conditions color was white, and the jaggery mixing conditions yielded a yellow color. In particular, by 

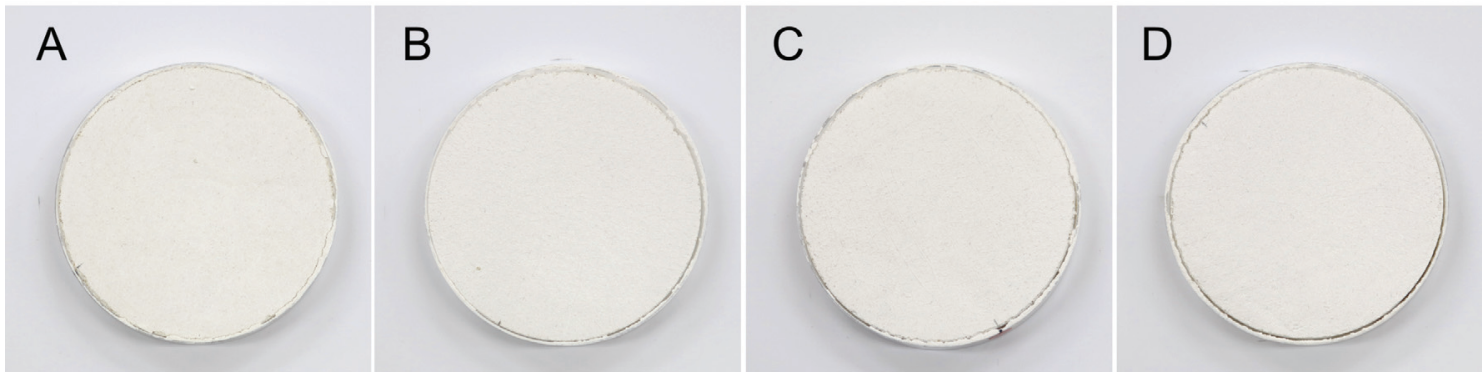

Figure 3. Surface of the filling agent samples (F1 group). (A) F1-J, (B) F1-S, (C) F1-P, (D) F1-W.
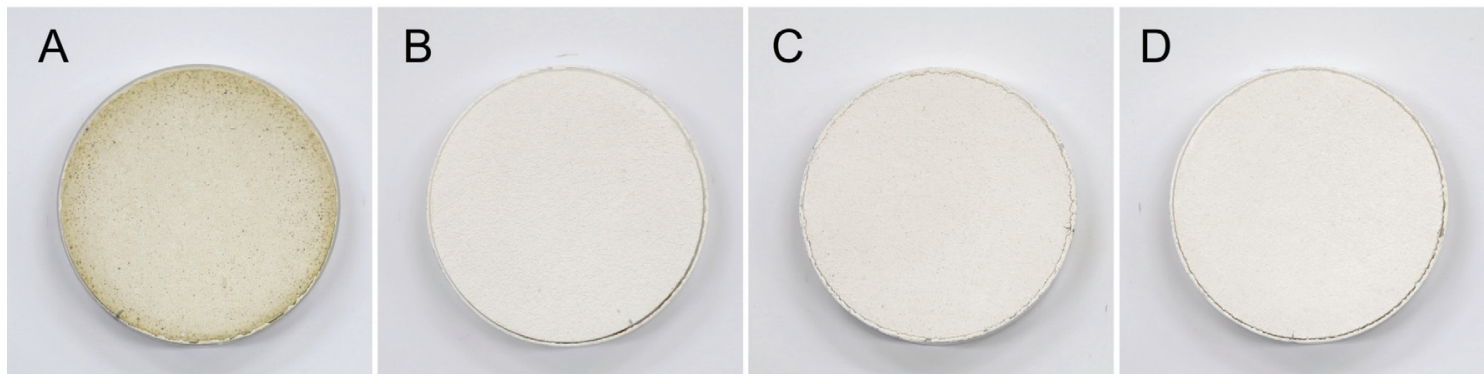

Figure 4. Surface of the filling agent samples (F2 group). (A) F2-J, (B) F2-S, (C) F2-P, (D) F2-W.
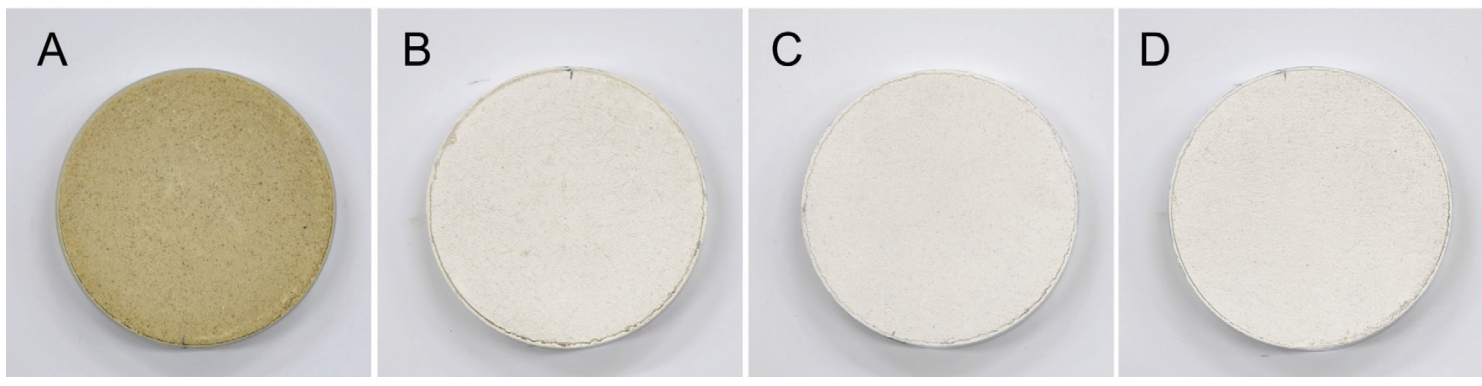

Figure 5. Surface of the filling agent samples (F3 group). (A) F3-J, (B) F3-S, (C) F3-P, (D) F3-W.

mixing in jaggery, as the sand mixing ratio increased, the distribution of yellow became more wide spread and the color became darker.

The chromaticity measurement confirmed a similar color trend. In the control group and the samples mixed with seaweed glue and primal, the $\mathrm{L}^{*}$ was higher than 90 , and the samples mixed with jaggery yielded a low $\mathrm{L}^{*}$ and a high $\mathrm{b}^{*}$
(Table 4). The higher the sand mixing ratio, the greater the change in $L^{*}$ and $b^{*}$ (Table 5). In the samples mixed with jaggery, which have large chromaticity differences, the low transparency and dark brown color of jaggery seemed to have influenced the color of the sand particles. According to Brady and Weil (2009), organic matter covers or darkens the bright colors of inorganic particles by covering them in the soil.

Table 4. Chromaticity results of the filling agent samples

\begin{tabular}{|c|c|c|c|c|c|c|c|c|c|c|c|c|}
\hline & \multicolumn{4}{|c|}{ F1 } & \multicolumn{4}{|c|}{$\mathrm{F} 2$} & \multicolumn{4}{|c|}{ F3 } \\
\hline & F1-J & F1-S & F1-P & F1-W & F2-J & F2-S & F2-P & $\mathrm{F} 2-\mathrm{W}$ & F3-J & F3-S & F3-P & F3-W \\
\hline $\mathrm{L}^{*}$ & 91.59 & 92.88 & 92.63 & 92.96 & 86.63 & 91.92 & 91.18 & 91.63 & 75.39 & 90.36 & 90.24 & 90.84 \\
\hline$a^{*}$ & 0.02 & 0.02 & 0.05 & 0.04 & -0.07 & -0.10 & 0.05 & -0.14 & 2.60 & -0.13 & 0.09 & -0.08 \\
\hline$b^{*}$ & 3.76 & 2.57 & 2.28 & 2.25 & 9.87 & 3.58 & 2.01 & 2.09 & 21.41 & 4.00 & 1.93 & 2.71 \\
\hline
\end{tabular}


Table 5. Color difference of the filling agent samples

\begin{tabular}{|c|c|c|c|c|c|c|c|c|c|c|c|c|}
\hline & \multicolumn{3}{|c|}{$\mathrm{J}$} & \multicolumn{3}{|c|}{$\mathrm{S}$} & \multicolumn{3}{|c|}{$\mathrm{P}$} & \multicolumn{3}{|c|}{ W } \\
\hline & $\triangle \mathrm{L}^{*}$ & $\triangle b^{*}$ & $\triangle \mathrm{E}$ & $\triangle \mathrm{L}^{*}$ & $\triangle \mathrm{b}^{*}$ & $\triangle \mathrm{E}$ & $\triangle \mathrm{L}^{*}$ & $\triangle b^{*}$ & $\triangle \mathrm{E}$ & $\triangle \mathrm{L}^{*}$ & $\triangle \mathrm{b}^{*}$ & $\triangle \mathrm{E}$ \\
\hline $\mathrm{F} 1 \longrightarrow \mathrm{F} 2$ & -4.96 & 6.11 & 7.87 & -0.96 & 1.01 & 1.40 & -1.45 & -0.27 & 1.48 & -1.33 & -0.16 & 1.35 \\
\hline $\mathrm{F} 2 \longrightarrow \mathrm{F} 3$ & -11.24 & 11.54 & 16.33 & -1.56 & 0.42 & 1.61 & -0.94 & -0.08 & 0.94 & -0.79 & 0.63 & 1.01 \\
\hline $\mathrm{F} 1 \rightarrow \mathrm{F} 3$ & -16.20 & 17.65 & 24.09 & -2.52 & 1.42 & 2.90 & -2.39 & -0.35 & 2.42 & -2.12 & 0.46 & 2.17 \\
\hline
\end{tabular}

Table 6. Results of physical properties of the filling agent samples

\begin{tabular}{|c|c|c|c|c|c|c|c|}
\hline & & \multirow{2}{*}{$\begin{array}{c}\text { Contraction } \\
(\%)\end{array}$} & \multirow{2}{*}{$\begin{array}{c}\text { Weight change } \\
(\%)\end{array}$} & \multirow{2}{*}{$\begin{array}{c}\text { Water content } \\
(\%)\end{array}$} & \multicolumn{3}{|c|}{ Compressive strength $\left(\mathrm{N} / \mathrm{mm}^{2}\right)$} \\
\hline & & & & & 7 days & 28 days & 56 days \\
\hline \multirow{4}{*}{ F1 } & F1-J & $1.89( \pm 0.02)$ & $18.44( \pm 0.39)$ & $18.99( \pm 0.28)$ & $1.68( \pm 0.04)$ & $1.47( \pm 0.25)$ & $2.22( \pm 0.18)$ \\
\hline & F1-S & $2.60( \pm 0.08)$ & $19.65( \pm 0.56)$ & $20.11( \pm 0.71)$ & $1.20( \pm 0.22)$ & $1.12( \pm 0.18)$ & $1.74( \pm 0.25)$ \\
\hline & $\mathrm{F} 1-\mathrm{P}$ & $2.44( \pm 0.12)$ & $18.56( \pm 0.24)$ & $20.05( \pm 0.25)$ & $1.51( \pm 0.14)$ & $1.68( \pm 0.02)$ & $2.51( \pm 0.31)$ \\
\hline & F1-W & $3.10( \pm 0.06)$ & $19.62( \pm 0.80)$ & $20.21( \pm 1.31)$ & $1.18( \pm 0.03)$ & $1.41( \pm 0.02)$ & $2.28( \pm 0.21)$ \\
\hline \multirow{4}{*}{$\mathrm{F} 2$} & F2-J & $1.83( \pm 0.07)$ & $12.85( \pm 0.68)$ & $13.07( \pm 0.53)$ & $1.64( \pm 0.09)$ & $1.42( \pm 0.13)$ & $2.66( \pm 0.04)$ \\
\hline & $\mathrm{F} 2-\mathrm{S}$ & $2.46( \pm 0.02)$ & $16.92( \pm 1.19)$ & $15.63( \pm 1.21)$ & $0.68( \pm 0.13)$ & $0.48( \pm 0.02)$ & $1.13( \pm 0.19)$ \\
\hline & F2-P & $2.06( \pm 0.23)$ & $13.19( \pm 0.52)$ & $13.69( \pm 0.81)$ & $1.35( \pm 0.07)$ & $1.40( \pm 0.03)$ & $2.32( \pm 0.14)$ \\
\hline & $\mathrm{F} 2-\mathrm{W}$ & $2.09( \pm 0.02)$ & $15.28( \pm 0.24)$ & $14.90( \pm 0.28)$ & $0.98( \pm 0.13)$ & $1.17( \pm 0.05)$ & $2.08( \pm 0.10)$ \\
\hline \multirow{4}{*}{$\mathrm{F} 3$} & F3-J & $1.73( \pm 0.12)$ & $11.89( \pm 0.74)$ & $10.45( \pm 0.70)$ & $1.37( \pm 0.17)$ & $1.55( \pm 0.14)$ & $2.13( \pm 0.15)$ \\
\hline & F3-S & $1.73( \pm 0.14)$ & $14.48( \pm 0.02)$ & $14.20( \pm 0.73)$ & $0.62( \pm 0.04)$ & $0.66( \pm 0.04)$ & $0.95( \pm 0.12)$ \\
\hline & F3-P & $1.60( \pm 0.12)$ & $11.33( \pm 0.28)$ & $11.29( \pm 0.42)$ & $1.12( \pm 0.06)$ & $1.09( \pm 0.09)$ & $2.00( \pm 0.40)$ \\
\hline & F3-W & $1.55( \pm 0.02)$ & $13.99( \pm 0.20)$ & $12.19( \pm 0.10)$ & $0.86( \pm 0.06)$ & $1.11( \pm 0.02)$ & $1.58( \pm 0.07)$ \\
\hline
\end{tabular}

\subsubsection{Physical properties}

Table 6 lists the evaluation results of the physical properties of the filling agents, according to the additives mixing ratios. The lower the sand mixing ratio, the higher the contraction was. The contraction ratio was $1.89 \%$ $3.10 \%, 1.83 \% \sim 2.46 \%$, and $1.55 \% \sim 1.73 \%$ when mixed at a ratio of $1: 1,1: 2$, and 1:3, respectively. The standard deviation of the contraction values by lime-sand mixing ratios were $1: 1(0.50 \%), 1: 2(0.26 \%)$, and $1: 3(0.09 \%)$, and the lower the sand mixing ratio, the greater the contraction variation depending on the additive. This result is because contraction is prevented by maintaining the volume ratio of reinforcing agents as the content of sand with a large particle size increases.

The weight change rate was $18.44 \% \sim 19.65 \%$ (F1 group), $12.85 \% \sim 16.92 \%$ (F2 group), and $11.33 \% \sim 14.48 \%$ (F3 group), and the water content was $18.99 \% \sim 20.21 \%$ (F1 group), $13.07 \% \sim 15.63 \%$ (F2 group), and $10.45 \% \sim 14.20 \%$ (F3 group). The weight change rate and water content were similar according to the mixing ratio conditions, and the higher the ratio of sand to lime, the lower the trend. The difference in weight change and water content occurred depending on the lime and sand content, because lime absorbs a large amounts of water due to its small particle size with large specific surface area, however, sand has a low absorption rate.

The higher the sand mixing ratio to lime, the lower the strength. This result is because the higher the content of sand, the larger the pores and the weaker the attraction forces are between the particles due to a larger volume ratio, thus reducing the strength. The sample strength decreased on day 28 of curing as compared to day 7, but generally increased by approximately $1.3 \sim 2.1$ times on day 56 of curing. The study by Hwang and Kang (2010) reported that lime gradually develops strength through a carbonation reaction during the curing period.

The condition of mixing jaggery and primal resulted in a lower contraction rate than the control group based on 1:1 and 1:2 mixing ratios. Under a 1:3 mixing ratio, the control group yielded lower contraction than the additive mixing 
conditions. The contraction deviation by additive type was in the order of the control group $(0.79 \%)$, seaweed glue $(0.47 \%)$, primal $(0.42 \%)$, and jaggery $(0.08 \%)$, and the contraction deviation was lower when mixing in the additives. It is likely that the additives aided in reducing the volume change during the drying process of the reinforcing agents. Similar contraction rates when mixing in jaggery, regardless of the lime and sand mixing ratio, prove this.

The weight change rate and the water content of the jaggery and primal mixing conditions were lower than the control group. This is because it was less affected by moisture as the additives increase the cohesion between the particles and reduces the porosity. According to a study by Lee et al. (2013b) and Moon (2019), a mixture of organic mediums in mortar made of soil increases the bond between soil particles, increasing the cohesion, and decreasing the number of pores.

The compressive strength results showed that the jaggery and primal mixing conditions were stronger than the control group. When jaggery was used as an additive to mortar, the mortar was more responsive to developing strength as compared to primal or seaweed glue.

\subsubsection{Discussion on the applicability}

Contraction and compressive strength demonstrated different trends depending on the content of lime and sand. When using jaggery and primal as mixing additives, the contraction of the reinforcing agent reduced and the compressive strength increased. In particular, lime mortar, which has a low sand content, demonstrated high strength but with a volume change due to contraction. If a filling agent with a large volume change is applied to cracks or fractures in a wall, it will not be able to reinforce the wall properly due to contraction. Additionally, too much stress within the reinforcing agent may cause physical damage, such as cracks in the reinforcing agent or flaking part of the wall when the reinforcing agent shrinks. Therefore, when applying filling agents to cracks or damaged areas, it is necessary to control the physical properties of the reinforcing agent, such as adjusting the sand mixing ratio in consideration of the volume change and strength, or mixing additives such as jaggery or primal.

\subsection{Grouting reinforcement agent experiment}

\subsubsection{Visual properties}

Contraction and cracks were observed on the surface of all the grouting agent samples. The sample mixed with jaggery showed irregular cracks around the center. In contrast, the control group and samples mixed with seaweed glue and primal showed circular cracks along the edges and some exfoliation (Figure 6). The area of the cracks were in the order of jaggery $(0.70 \%)$, primal $(0.67 \%)$, control group $(0.57 \%)$, and seaweed glue $(0.54 \%)$. The cracks arose because the stress inside the samples reduced the volume as the moisture evaporated. The samples mixed with jaggery

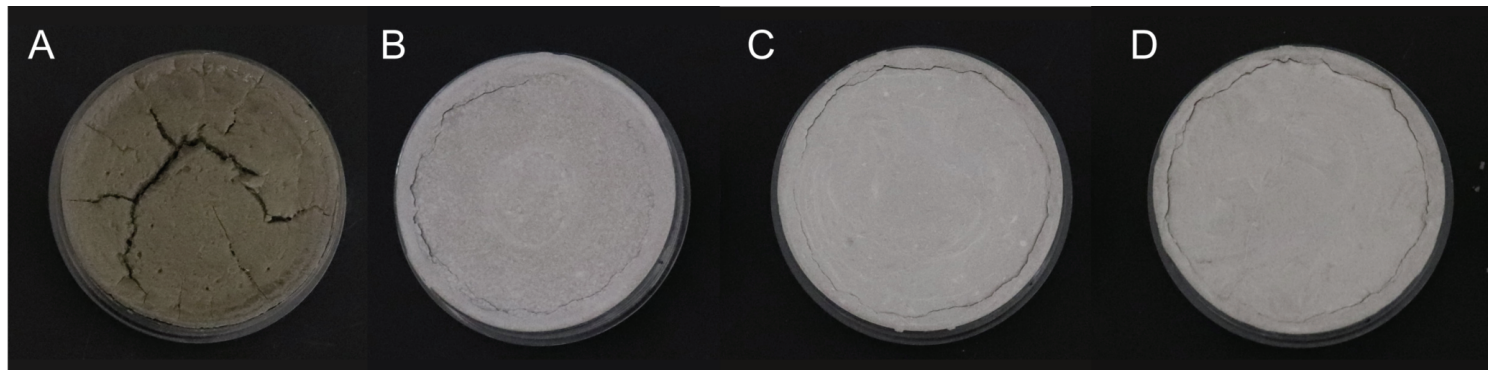

Figure 6. Surface of the grouting agent samples. (A) G-J, (B) G-S, (C) G-P, (D) G-W.

Table 7. Chromaticity results of the grouting agent samples

\begin{tabular}{|c|c|c|c|c|}
\hline & G-J & G-S & G-P & G-W \\
\hline $\mathrm{L}^{*}$ & 45.67 & 68.73 & 72.77 & 72.25 \\
\hline$a^{*}$ & 1.10 & 0.29 & 0.23 & 0.32 \\
\hline$b^{*}$ & 10.54 & 5.59 & 4.20 & 4.60 \\
\hline
\end{tabular}


were brown, but the other samples were gray.

The chromaticity of the samples mixed with primal and the control group were similar in the range of $\mathrm{L}^{*} 72.25$ $72.77, a^{*} 0.23 \sim 0.32$, and $b^{*} 4.20 \sim 4.60$. The chromaticity of the samples mixed with jaggery were $\mathrm{L}^{*} 45.67, \mathrm{a}^{*} 1.10$, and $b^{*} 10.54$, and the samples mixed with seaweed glue were $L^{*}$ 68.73, $a^{*} 0.29$, and $b^{*} 5.59$ (Table 7). The samples mixed with jaggery and seaweed glue exhibited a lower $\mathrm{L}^{*}$ and a higher $b^{*}$ than the control group and the samples mixed with primal. In particular, the samples mixed with jaggery showed a large difference in the brightness and saturation values as compared to the other additive conditions.

\subsubsection{Physical properties}

Table 8 lists the physical properties results of the grouting agents according to their additives. By comparison with the control group, the contraction rate was more significant when mixing the additives. The deviation from the authentic sample without contraction was in the order of jaggery $(-0.88 \mathrm{~mm})$, seaweed glue $(-0.81 \mathrm{~mm})$, primal $(-0.70 \mathrm{~mm})$, and the control group $(-0.59 \mathrm{~mm})$, similar to the contraction rate trend (Figure 7). The contraction rate value generated by the grouting agent was approximately 10 times higher than the filling agent. This is because of the large stress introduced into the grouting agent during evaporation of the moisture contained in the additives, and the increased amount of additives as the grouting agent requires fluidity.

The weight change rate and water content of the samples mixed with jaggery and primal were lower than that of the control group. This is due to the difference in moisture content and contraction according to the mixing additives within the same particle size, and because the additives contributed to the dense distribution of particles constituting the grouting agent, which decreases the porosity.

All the additive mixing conditions had higher compressive strength than the control group. In particular, the primal mixing condition was approximately four times higher than the control group, and also higher than the other additive

Table 8. Results of physical properties of the grouting agent samples

\begin{tabular}{ccccc}
\hline & G-J & G-S & G-P & G-W \\
\hline Contraction (\%) & $20.94( \pm 1.98)$ & $18.72( \pm 1.03)$ & $16.58( \pm 1.28)$ & $14.48( \pm 2.33)$ \\
\hline Weight change (\%) & $22.25( \pm 0.05)$ & $23.75( \pm 0.29)$ & $21.98( \pm 0.03)$ & $22.89( \pm 1.18)$ \\
\hline Water content $(\%)$ & $20.81( \pm 0.02)$ & $25.91( \pm 0.25)$ & $25.30( \pm 0.13)$ & $26.41( \pm 0.18)$ \\
\hline Compressive strength $\left(\mathrm{N} / \mathrm{mm}^{2}\right)$ & $1.21( \pm 0.05)$ & $0.83( \pm 0.11)$ & $2.30( \pm 0.14)$ & $0.64( \pm 0.13)$ \\
\hline Vscosity $(\mathrm{cP})$ & $7008( \pm 529)$ & $13692( \pm 676)$ & $8012( \pm 586)$ & $5936( \pm 635)$ \\
\hline Ahesion $(\mathrm{MPa})$ & $0.42( \pm 0.13)$ & $0.52( \pm 0.10)$ & $0.26( \pm 0.01)$ & $0.23( \pm 0.01)$ \\
\hline
\end{tabular}
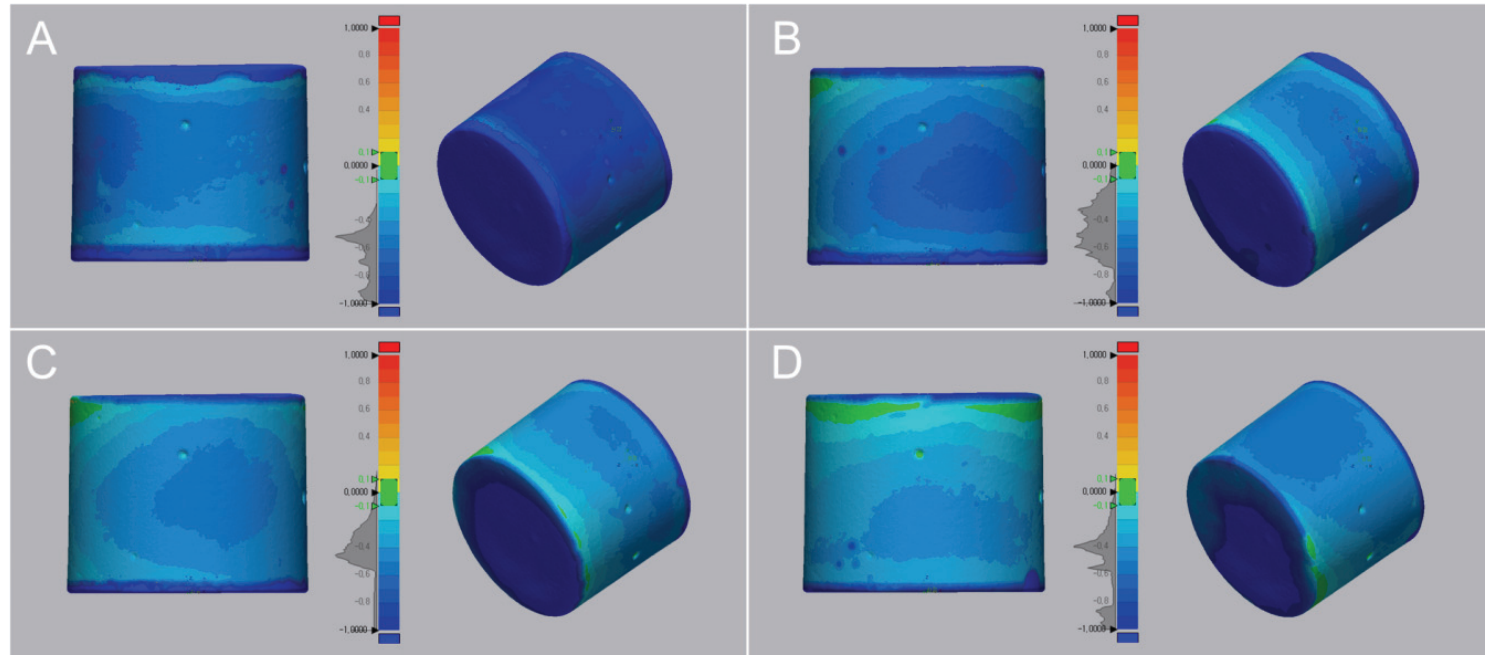

Figure 7. 3D deviation maps of the grouting agent samples. (A) G-J, (B) G-S, (C) G-P, (D) G-W. 
mixing conditions. Therefore, primal is more responsive in developing mortar strength than jaggery or seaweed glue.

Viscosity decreased in the order of seaweed glue, primal, jaggery, and the control group. Generally, the additive mixing conditions were more viscous than the control group. The adhesive strength decreased in the order of seaweed glue, jaggery, primal, and the control group. The additive mixing conditions also showed higher adhesive strength than the control group. In particular, the seaweed glue mixing condition exhibited higher viscosity and adhesion than the other additive mixing conditions. This is due to the correlation between the viscosity of the reinforcing agent and the adhesive strength. The difference in viscosity is related to the fluidity and affects the adhesive strength (Lee et al., 2013a as cited in Choi, 1990).

\subsubsection{Discussion on the applicability}

Different properties were observed in compressive strength and adhesion according to the additives mixed into the reinforcing agents. This highlights that high strength reinforcing agents do not always exhibit high adhesion. High strength reinforcing agents improve durability, but excessive differences in strength from the original wall may cause damage due to differences in the physical properties between the wall and the reinforcing agents. In contrast, reinforcing agents with low adhesive strength cannot stably reinforce the gaps and will not function as reinforcing agents. Additionally, if the fluidity of the grouting agent decreases depending on the viscosity conditions, its workability may be degraded during conservation treatment. When applying grouting agents to areas with separation between layers, the grouting process should be divided into several intervals to minimize volume change. The optimal reinforcing agent should be selected by considering physical properties such as strength, viscosity, and adhesive strength according to the conditions of the target.

\section{CONCLUSION}

This study conducted tests on reinforcement agents for the conservation treatment of murals in the Payathonzu temple in Bagan, Myanmar. To effectively evaluate their properties, the reinforcement agents were divided into filling reinforcement agents for cracked or damaged areas and grouting reinforcement agents to fill the gaps between the layers caused by deformation and separation. As a result of the study, the following conclusions were obtained by summarizing the reinforcing agent properties according to the reinforcement agent mixing ratios and additive conditions:

1. The surface of the filling reinforcement agent exhibited no cracks in all conditions, however contraction was evident. The whiteness of the samples mixed with seaweed glue and primal increased to a similar level as that of the control group while drying the samples, and the yellowness increased in the samples mixed with jaggery.

2. According to the filling reinforcement agent mixing ratios, the physical properties exhibited significant weight and volume changes when the lime and sand contents were the same, but it exhibited high strength. In contrast, the higher the sand content in lime, the lesser the physical changes, such as contraction, and the lower the strength.

3. The samples mixed with jaggery and primal exhibited a lower contraction, lower water content, and higher strength when compared to the control group. The samples mixed with jaggery exhibited similar contractions regardless of the sand mixing ratios, and less contraction occurred in the conditions with low sand mixing ratios.

4. The filling reinforcement agents with a low sand content can reduce cracking in the material or separation between reinforced areas due to changes in the volume ratio by using additives, and increases the strength of reinforcing agents with a high sand content.

5. The grouting reinforcement agent samples exhibited higher strength and adhesion as compared to the control group by mixing additives with similar particle sizes. Among the additives, the samples mixed with primal showed high strength while the samples with seaweed glue exhibited high viscosity and adhesive strength.

6. Conditions that cause significant contraction of the grouting reinforcement agents result in the gaps not being properly filled due to volume changes or creates damage, such as cracks, due to excessive internal stress. Therefore, grouting reinforcement agents with adequate fluidity should be ensured to be effectively injected and to develop adhesion after injection. A reinforcement process of dividing the grouting process into several intervals will be necessary to minimize contraction. 
The filling and grouting reinforcement experiments showed that the properties of the reinforcing agents differ according to the mixing ratios and additive conditions. The relationship between the physical properties, such as contraction and compressive strength, according to each condition can be important for predicting the phenomenon that may occur after applying the reinforcing agents. Therefore, the murals in Payathonzu temple can be reinforced through more stable conservation treatment in the future with the support of additional tests and inspections under various conditions.

\section{REFERENCES}

Ahn, S.A., Kim, E.K., Nam, B.G., Hlaing, C.S.S. and Kang, S.Y., 2018, Mineralogical and physical properties of lime plaster used in wall repair in temple of Bagan, Myanmar. Journal of the Mineralogical Society of Korea, 31(4), 267-275. (in Korean with English abstract)

Baekje Cultural Properties Research Institute, 2010, A report on conservation of the white-robed Kuan-Yin mural painting in main buddha hall of Naesosa Buddhist Temple. 107-109. (in Korean)

Beril, B.S. and Leslie, R., 2013, Evaluation of lime-based hydraulic injection grouts for the conservation of architectural surfaces: A manual of laboratory and field test methods. Getty Conservation Institute, Los Angeles, 105.

Beril, B.S. and Leslie, R., 2014, Field test methods for comparative evaluation of lime-based hydraulic injection grouts for the conservation of architectural surfaces. ICOM-CC 17th Triennial Conference Preprints, Melbourne, Paris, September 15-19, 10.

Brady, N.C. and Weil, R.R., 2011, Elements of the nature and properties of soils. Kyobobook, Seoul, 110. (Original work published in 2009)

Cho, H.J., Lee, T.J., Lee, H.S. and Chung, Y.J., 2017, Study on physical change in the earthen finish layer of tomb murals due to drying. MUNHWAJAE Korean Journal of Cultural Heritage Studies, 50(4), 148-165. (in Korean with English abstract)

Choi, S.Y., 1990, Principle and theory of adhesive. Journal of the Korea Institute of Rubber Industry, 25, 291-309. (in Korean)

Francesca, C., Giacomo, C. and Simon, S., 2005, Evaluation of binder/aggregate ratios in archaelogical lime mortars with carbonate aggregate: A comparative assessment of chemical, mechanical and microscopic approaches. Archaeometry, 47(4), 671-689.

Hwang, H.Z. and Kang, N.Y., 2010, Preliminary study on traditional earth construction technique use of lime.
Journal of the KIEAE, 10(2), 3-8. (in Korean with English abstract)

Isobel, G., 2004, Pozzolanas as additives for grouts - An investigation of their working properties and performance characteristics. Studies in Conservation, 49(1), 23-34.

Kim, S.K. and Jeong, H.Y., 2008, Study on the filling material for the painting wall layer of the temple wall painting using a natural adhesive. National Research Institute of Cultural Heritage. 29, 255-278. (in Korean with English abstract)

Korea Culture Heritage Foundation, Konkuk University and Chungbuk National University, 2018, A study on the current state of temple murals of Bagan ruins and methods of conserving mural paintings of Payathonzu temple. 259.

Korea Culture Heritage Foundation, Konkuk University and Chungbuk National University, 2019, Scientific analysis of materials and making conservation manual for Bagan murals. 167.

Lee, H.S., Han, K.S. and Lee, S.J., 2013a, A study on painting layer fixative processing of mural paintings of buddhist temples in Korea. Journal of Conservation Science, 29(1), 81-92. (in Korean with English abstract)

Lee, H.S., Kim, S.H. and Han, K.S., 2019, Diagnosis and evaluation of conservation state of mural paintings in Payathonzu temple on Bagan Heritage Site in Myanmar. Journal of Conservation Science, 35(5), 494-507. (in English)

Lee, K.M., Lee, H.S. and Han, K.S., 2013b, Study on application of filling material for reinforcement of soil murals in buddhist temple. Journal of Conservation Science, 29(4), 395-406. (in Korean with English abstract)

Miguel, A.C. and Mahasti, A., 1993, Art and eternity: The Nefertari Wall Paintings Conservation Project 19861992. Getty Conservation Institute, Santa Monica, 160.

Moon, H.Y., 2018., Study on properties and manufacturing methods of soil mural's finishing layer depending on type and concentration of natural adhesive. Master's thesis, Korea National University of Cultural Heritage, Buyeo, 54-55. (in Korean with English abstract)

Piero, B., Luigi, D., Francesca, P., Giuseppe, S. and Enzo, F., 1997, New autogenous lime-based grouts used in the conservation of lime-based wall paintings. Studies in Conservation, 42(1), 43-54.

Rodolfo, L.L., 2018, Technical recommendations to improve the use of materials, techniques and methodologies for the conservation of architectural decorative works at Pagán. UNESCO, Rome, 19.

Stephen, R., Lisa, S., Fan, Z., Tang, W., Qiao, H. and Yang, J., 2010, Implementation of grouting and salts-reduction 
treatments of Cave 85 wall paintings. Conservation of ancient sites on the Silk Road: Proceedings of the Second International Conference on the Conservation of Grotto Sites, Mogao Grottoes, Dunhuang, People's Republic of China, Los Angeles, June 28-July 3, 480-487.

The International Centre for the Study of the Preservation and Restoration of Cultural Property, 1982, Mortars, cements and grouts used in the conservation of historic buildings. Mortiers, ciments et coulis utilisés dans la conservation des bâtiments historiques Symposium, Rome, November 3-6, 414.
The International Centre for the Study of the Preservation and Restoration of Cultural Property, 1993, Conservation of mural paintings, external stuccoes and steone Buildings. UNESCO, Paris, 62.

Yu, Y.G. and Lee, H.S., 2019, The application of natural hydraulic lime as a reinforcing agent for mural paintings in ancient tombs. Conservation Science in Museum, 21, 29-40. (in Korean with English abstract) 